DOI: 10.1016/j.forsciint.2012.06.017

\title{
Interference of fetal hemoglobin in the determination of carboxyhemoglobin by spectrophotometry
}

\author{
Lucie Vaillancourt*1 $^{*}$ Brigitte Desharnais ${ }^{1,2}$ | Nathalie Goudreau ${ }^{1}$ | Pascal Mireault ${ }^{1}$
}

\author{
${ }^{1}$ Department of Toxicology, Laboratoire de \\ sciences judiciaires et de médecine légale, \\ 1701 Parthenais Street, Montréal, Québec, \\ Canada \\ ${ }^{2}$ Department of Chemistry \& Biochemistry, \\ Concordia University, 7141 Sherbrooke \\ Street West, Montréal, Québec, Canada \\ Correspondence \\ *Lucie Vaillancourt, 1701 Parthenais Street, \\ Montréal, Québec, Canada, H2K 3S7. \\ Email: lucie.vaillancourt@msp.gouv.qc.ca
}

\begin{abstract}
Determination of carboxyhemoglobin ( $\mathrm{HbCO})$ is routinely performed in suspected cases of carbon monoxide intoxication and unexplained deaths. However, some authors have suggested that measured $\mathrm{HbCO}$ may be falsely elevated in infants ( 0 12 months) due to the presence of fetal hemoglobin (HbF). The purpose of this study was to evaluate the impact of fetal hemoglobin on the spectrophotometric determination of carboxyhemoglobin. The interference of $\mathrm{HbF}$ in the determination of $\mathrm{HbCO}$ in infants aged from 0 to 12 months was evaluated using 16 ante-mortem and 19 post-mortem blood samples. The $\% \mathrm{HbCO}$ was quantified spectrophotometrically by calculating the $560 \mathrm{~nm} / 530 \mathrm{~nm}$ absorbance ratio, using a dual beam spectrophotometer. The average measured $\mathrm{HbCO}$ in infants of 3 months of age or under was $17 \%$, which is abnormally elevated. No significant difference in $\mathrm{HbCO}$ measurement was found between ante-mortem and post-mortem samples. These results highlight the fact that care must be taken in interpretation of carboxyhemoglobin measurements in infants when using a spectrophotometric method.
\end{abstract}

\section{KEYWORDS:}

Forensic toxicology, carboxyhemoglobin, fetal hemoglobin, spectrophotometry, neonates, false positive

\section{1 | INTRODUCTION}

Carbon monoxide (CO) is a gaseous product of the incomplete combustion of organic matter such as wood or fuel. When CO is inhaled, it binds with hemoglobin ( $\mathrm{Hb}$ ) to form carboxyhemoglobin ( $\mathrm{HbCO}$ ). Hemoglobin has an affinity for $\mathrm{CO}$ that is 250 times larger than oxygen $\left(\mathrm{O}_{2}\right)$; therefore, at high $\mathrm{CO}$ levels, hemoglobin cannot accomplish its oxygen delivery duties ${ }^{1}$. Although the mechanisms are not completely understood, myoglobin, cytochromes and chemical mediators are also suspected to be involved in $\mathrm{CO}$ toxicity ${ }^{2}$. Levels of $\mathrm{HbCO}$ up to $10 \%$ in smokers are considered normal, whereas levels between $20 \%$ and $50 \%$ are toxic and levels above $50 \%$ are lethal ${ }^{3}$. Carbon monoxide intoxication is typically observed in cases of residential or commercial fires, industrial accidents, heating systems (oil, propane, fireplaces) and suicide through car exhaust inhalation. HbCO can be quantified in blood by gas chromatography, with an oxygen electrode, or by obtaining the absorption spectrum using a spectrophotometer ${ }^{4}$ or a CO-oximeter ${ }^{5}$. The spectrophotometric measurement is very popular because it is simple, accurate, rapid and accessible ${ }^{6}$. However, it is reported that spectrophotometric measurement of $\mathrm{HbCO}$ can be subject to interferences from fetal hemoglobin $(\mathrm{HbF})^{7,8}$. Fetal hemoglobin is structurally similar to adult hemoglobin $(\mathrm{HbA})$ but can bind oxygen with greater affinity $^{2}$. At birth, $\mathrm{HbF}$ accounts for around $75 \%$ of total hemoglobin, decreasing drastically at 4 months of age and reaching a level close to zero in adult blood ${ }^{9}$. The absorption spectrum for fetal hemoglobin is very similar to adult hemoglobin, but the absorption coefficients differ ${ }^{10}$, because of a hypsochromic shift in the oxygen dissociation curve of HbF compared to adult 
hemoglobin ${ }^{11}$. These small differences are the likely cause of reported inaccuracy in the spectrophotometric quantification of $\mathrm{HbCO}$ in neonates ${ }^{12}$. Studies on this topic yield contradictory results. Vreman et al. ${ }^{7}$ and Mehrotra et al. ${ }^{8}$ report that spectrophotometric measurement of $\mathrm{HbCO}$ is falsely elevated by the presence of $\mathrm{HbF}$, giving false positive results up to $8 \%$ when using a CO-oximeter. Zwart et al. ${ }^{13}$ and Variend et al. ${ }^{14}$ report that in the method proposed by Katsumata et al. ${ }^{4}$, reduction of blood with sodium dithionite eliminates the interference of $\mathrm{HbF}$, and thus should not give positive bias when using a basic spectrophotometer. In this paper, using the Katsumata et al. ${ }^{4}$ method, the impact of the infant's age on determination of $\mathrm{HbCO}$ is studied in 35 cases under one year of age. Comparison between ante-mortem and postmortem blood samples is performed. The effect of increasing the concentration of sodium dithionite, as well as increasing the incubation time, is also examined.

\section{2 | METHODS}

\section{1 | Materials}

Sodium carbonate (certified ACS, 100.0\%) and sodium hydroxide (certified ACS, 99.0\%) were obtained from Fisher Scientific (Fair Lawn, NJ, USA). Sodium dithionite (technical grade, 85\%) was obtained from Sigma-Aldrich (St. Louis, MO, USA). HbCO standards were obtained from Instrumentation Laboratory (Bedford, MA, USA). A Perkin Elmer UV/Vis Spectrophotometer Lambda 35 was used to perform the spectrophotometric analysis. Minitab 17 (Minitab Inc., State College, PA, USA) and Excel (Microsoft, Redmond, WA, USA) were used to perform statistical calculations and generate plots.

\section{2 | Ante-mortem and post-mortem blood sampling}

All infants studied were under 1 year of age. Ante-mortem venous blood samples $(n=16)$ were obtained from the pediatric hospital as excess from routine blood work. Blood was collected in BD Vacutainer tubes (lavender cap) containing EDTA and stored at $4{ }^{\circ} \mathrm{C}$. In post-mortem cases $(n=19)$, femoral and cardiac blood, when available, were sampled during the autopsy from infants who died in circumstances unrelated to the presence of carbon monoxide (e.g. shaken baby syndrome, dog attack, co-sleeping). Femoral blood was collected through a disposable needle inserted in the femoral vein. The femoral vein was unclamped during this operation and 1 to $10 \mathrm{~mL}$ of the available femoral blood was collected. Average femoral blood volume collected was $2 \mathrm{~mL}$. Samples were stored at $4{ }^{\circ} \mathrm{C}$ in BD Vacutainer tubes (grey cap) containing $100 \mathrm{mg}$ sodium fluoride and $20 \mathrm{mg}$ potassium oxalate. Cardiac blood samples consisted of pooled cardiac blood (left and right ventricles) that flowed out of the heart after the aorta was sectioned. Average cardiac blood volume was $5 \mathrm{~mL}$ but ranged from 2 to $50 \mathrm{~mL}$. Samples were stored at $4{ }^{\circ} \mathrm{C}$ in Starplex Leakbuster polypropylene containers without any preservative. Given the short time interval between the collection of the samples and the analysis (0-72 hours), no stability issue was expected.

\subsection{Spectrophotometric quantification}

The $\mathrm{HbCO}$ quantification method was based on the work of Katsumata et al. ${ }^{4,15}$. Briefly, $50 \mu \mathrm{L}$ of blood was diluted in $5 \mathrm{~mL}$ of $1 \mathrm{mg} / \mathrm{mL}$ sodium carbonate and vortexed. Then $20 \mathrm{mg}$ of sodium dithionite and $500 \mu \mathrm{L}$ of $1 \mathrm{~N}$ sodium hydroxide were added to the solution, with vortexing after each addition. The sample was allowed to rest for approximately 1 minute between the addition of sodium dithionite and that of $\mathrm{NaOH}$. An aliquot of this solution was then transferred to a $1 \mathrm{~cm}$ path length disposable plastic absorbance cell. The absorbance spectrum from $500 \mathrm{~nm}$ to $650 \mathrm{~nm}$ was obtained using a double-beam spectrophotometer, with sodium carbonate solution as the reference sample. Absorbance maxima measured around $530 \mathrm{~nm}$ and $560 \mathrm{~nm}$ were used to quantify $\mathrm{HbCO}$ using Equation 1.

$$
\mathrm{HbCO}(\%)=\left(2.21-A_{560} / A_{530}\right) \times 79
$$

The constants in Equation 1 were obtained empirically using prepared standards of 5\%, 20\% and 50\% $\mathrm{HbCO}$. This method was validated according to ISO 17025 and CAN-P-1578 guidelines (Canadian guidelines for the accreditation of forensic testing laboratories). Sodium dithionite should convert all forms of hemoglobin (e.g. hemoglobin, methemoglobin, oxyhemoglobin) into reduced hemoglobin $(\mathrm{HHb})$ except for carboxyhemoglobin, providing a uniform system of $\mathrm{HbCO}$ and $\mathrm{HHb}$. The addition of sodium hydroxide clears the turbidity of the sample and allows a better spectrophotometric separation of the peaks of reduced hemoglobin and carboxyhemoglobin. The spectra of the two components combine to form two distinct peaks at $530 \mathrm{~nm}$ and $560 \mathrm{~nm}$. The absorbance ratio of these two peaks changes linearly with $\mathrm{HbCO}$ concentration in blood. 


\section{4 | Evaluation of sodium dithionite impact}

The impact of sodium dithionite on the reduction of blood was evaluated by varying the mass added and the time of incubation after addition. Five samples from infants with a high \% $\mathrm{HbCO}$ were analyzed according to the method described above except that the mass of sodium dithionite added to the sample was tripled $(60 \mathrm{mg})$ and the incubation time was extended to 5 or 30 minutes after the addition and vortexing.

\section{3 | RESULTS}

\section{1 | Quantification of $\mathrm{HbCO}$ in neonates}

A typical spectrum of neonate blood is shown in Figure 1 . The calculated results for neonates studied are presented in Table 1 . The apparent levels of $\mathrm{HbCO}$ in infants under 3 months of age $(n=30)$ varies between $4.3 \%$ and $26.9 \%$, while it is under $5 \%$ in infants between 4 and 11 months of age $(n=5)$ for both ante-mortem and post-mortem infants.

FIGURE 1 Absorption spectrum of a blood sample. (1) Peak absorbance of $\mathrm{HbCO}$ at $530 \mathrm{~nm}$. (2) Peak absorbance of $\mathrm{HHb}$ at $560 \mathrm{~nm}$.

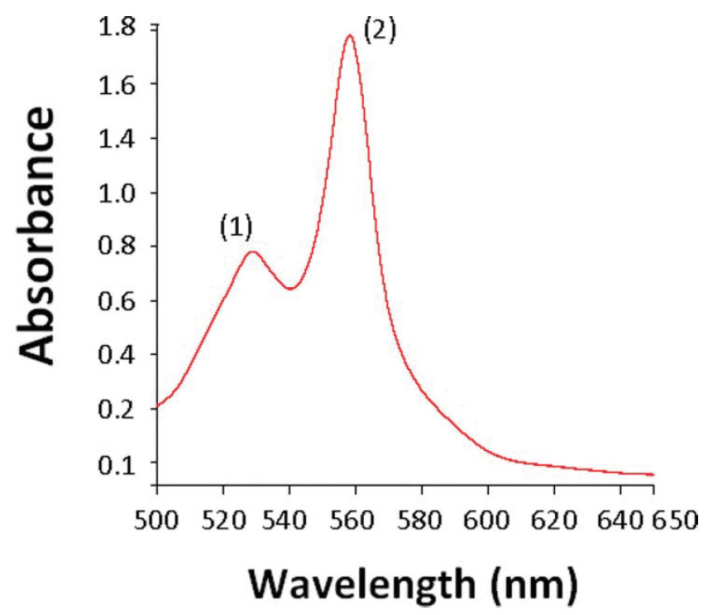

Figure 2 shows that apparent $\mathrm{HbCO}$ decreases with age in both groups, and correlates with the expected decrease of fetal hemoglobin concentration in blood ${ }^{9}$. Prediction lines at the $95 \%$ confidence level, which represents the range in which a single new observation is likely to fall given the predictors, is also shown in Figure 2 . It shows that $\mathrm{HbCO}$ values of $14 \%$ to $34 \%$ can be obtained at an age of 2 weeks, whereas this interval goes down to $0 \%$ to $21 \%$ at 3 months.

\subsection{Impact of sodium dithionite}

Results of the tests with sodium dithionite are shown in Table 2 for the 5 cases studied. No significant change from baseline value was observed when increasing the quantity of sodium dithionite threefold and increasing the time of incubation to 5 minutes ( $p=0.447)$ or 30 minutes $(p=0.101)$. The expected effect was that sodium dithionite would reduce $\mathrm{HbF}$ to $\mathrm{HHb}$, therefore eliminating the $\mathrm{HbF}$ interference. This would then translate to a lower level of measured HbCO. However, in the majority of cases, an increase of the $\% \mathrm{HbCO}$ was observed. This shows that sodium dithionite does not eliminate the HbF interference.

\section{3 | Comparison of ante-mortem and post-mortem cases}

The first order slope was obtained by least squares linear regression for \% $\mathrm{HbCO}$ value against age in post-mortem cases and in ante-mortem cases. There was no significant difference between slopes of ante-mortem $(m=-3.54)$ and post-mortem $(m=$ 
TABLE 1 Results for $\mathrm{HbCO}(\%)$ in infants.

\begin{tabular}{|c|c|c|c|c|}
\hline Case number & Ante/Post-mortem & Type of blood & Age (months) & $\% \mathrm{HbCO}$ \\
\hline 1 & Ante & Whole & 1 & 24.7 \\
\hline 2 & Ante & Whole & 2 & 10.6 \\
\hline 3 & Ante & Whole & 0.75 & 20.0 \\
\hline 4 & Ante & Whole & 7 & 1.9 \\
\hline 5 & Ante & Whole & 2 & 22.9 \\
\hline 6 & Ante & Whole & 0.5 & 24.0 \\
\hline 7 & Ante & Whole & 6 & 1.6 \\
\hline 8 & Ante & Whole & 0.5 & 13.0 \\
\hline 9 & Ante & Whole & 0.5 & 19.0 \\
\hline 10 & Ante & Whole & 0.5 & 18.0 \\
\hline 11 & Ante & Whole & 0.75 & 20.0 \\
\hline 12 & Ante & Whole & 3 & 8.1 \\
\hline 13 & Ante & Whole & 0.75 & 17.0 \\
\hline 14 & Ante & Whole & 0.5 & 22.0 \\
\hline 15 & Ante & Whole & 4 & 1.3 \\
\hline 16 & Ante & Whole & 1.75 & 16.0 \\
\hline 17 & Post & Cardiac & 2 & 9.0 \\
\hline \multirow[t]{2}{*}{18} & Post & Cardiac & 1.75 & 10.0 \\
\hline & & Femoral & 1.75 & 12.0 \\
\hline \multirow[t]{2}{*}{19} & Post & Cardiac & 1.25 & 17.7 \\
\hline & & Femoral & 1.25 & 24.1 \\
\hline \multirow[t]{2}{*}{20} & Post & Cardiac & 3 & 13.4 \\
\hline & & Femoral & 3 & 26.9 \\
\hline \multirow[t]{2}{*}{21} & Post & Cardiac & 0.5 & 24.0 \\
\hline & & Femoral & 0.5 & 23.0 \\
\hline 22 & Post & Cardiac & 2 & 18.0 \\
\hline 23 & Post & Cardiac & 1.75 & 10.0 \\
\hline \multirow[t]{2}{*}{24} & Post & Cardiac & 0 & 24.0 \\
\hline & & Femoral & 0 & 24.0 \\
\hline \multirow[t]{2}{*}{25} & Post & Cardiac & 0.5 & 19.0 \\
\hline & & Femoral & 0.5 & 20.0 \\
\hline 26 & Post & Cardiac & 2 & 8.3 \\
\hline \multirow[t]{2}{*}{27} & Post & Cardiac & 3 & 6.4 \\
\hline & & Femoral & 3 & 9.3 \\
\hline 28 & Post & Cardiac & 1.5 & 19.0 \\
\hline 29 & Post & Cardiac & 0.25 & 20.0 \\
\hline 30 & Post & Cardiac & 0.25 & 25.0 \\
\hline 31 & Post & Cardiac & 2.5 & 7.4 \\
\hline 32 & Post & Femoral & 11 & 4.0 \\
\hline \multirow[t]{2}{*}{33} & Post & Cardiac & 1 & 19.0 \\
\hline & & Femoral & 1 & 24.0 \\
\hline \multirow[t]{2}{*}{34} & Post & Cardiac & 3 & 4.3 \\
\hline & & Femoral & 3 & 6.3 \\
\hline 35 & Post & Cardiac & 6 & 3.0 \\
\hline
\end{tabular}

-4.84 ) cases at a 95\% confidence level ( $p=0.56$ ), showing that there is no significant difference in the rate of decrease of the interference with age. Additionally, there is no significant difference between the y-intercept of ante-mortem $(b=22.0)$ and postmortem $(b=23.7)$ cases at a 95\% confidence level $(p=0.46)$. In conjunction with the lack of significant difference between the slopes, this shows that ante-mortem and post-mortem cases suffer from similar interference due to the presence of $\mathrm{HbF}$. 
FIGURE 2 Quantified $\mathrm{HbCO}(\%)$ in neonates of 0 to 11 months. Prediction interval lines are shown for the 0 to 3 months regression.

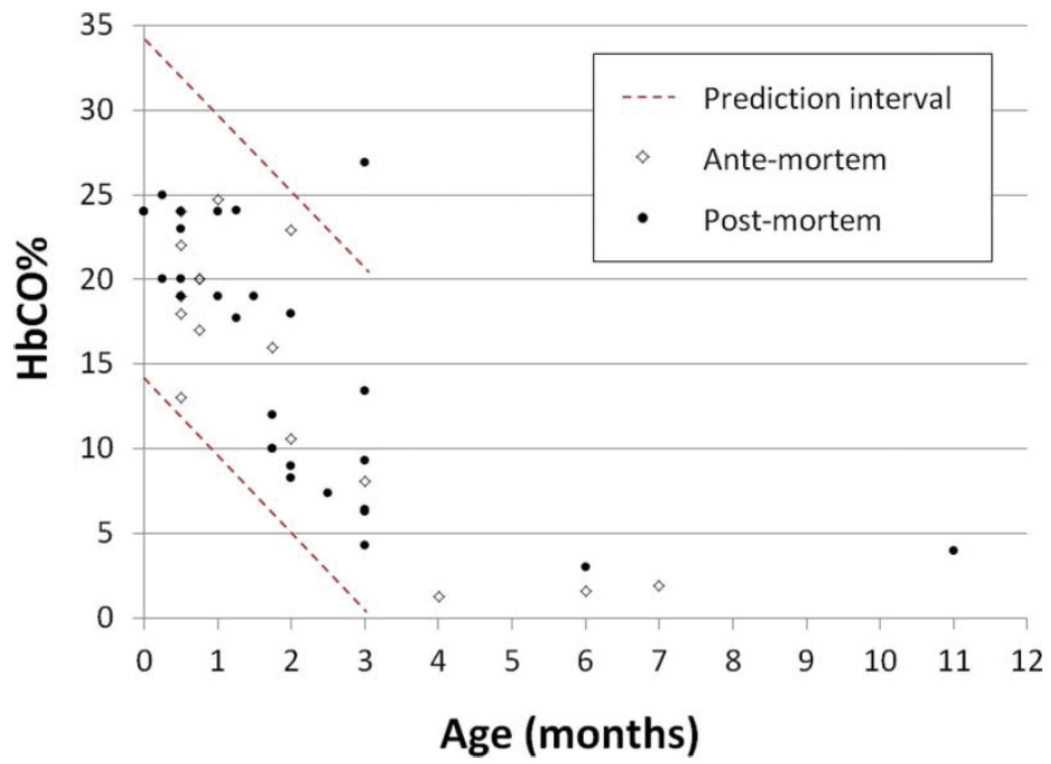

TABLE 2 Comparison of $\% \mathrm{HbCO}$ between expected values and new conditions of blood reduction by sodium dithionite in 5 cases.

\begin{tabular}{lccc}
\hline Case number & $\begin{array}{c}\text { Reference } \\
\text { 1x dithionite (20mg) } \\
\text { Incubation : 1 min } \\
(\% \mathrm{HbCO})\end{array}$ & $\begin{array}{c}\text { Test \#1 } \\
\text { 3x dithionite }(60 \mathrm{mg}) \\
\text { Incubation : 5 min } \\
(\% \mathrm{HbCO})\end{array}$ & $\begin{array}{c}\text { Test \#2 } \\
\text { 3x dithionite (60mg) } \\
\text { Incubation : 30 min } \\
(\% \mathrm{HbCO})\end{array}$ \\
\hline 1 & 20 & 22 & 23 \\
2 & 19 & 26 & 24 \\
3 & 20 & 22 & 27 \\
4 & 16 & 14 & 15 \\
5 & 12 & 10 & 13 \\
\hline
\end{tabular}

\subsection{Comparison of cardiac and femoral blood}

A paired t-test was performed between cardiac and femoral $\mathrm{HbCO}(\%)$. Results show that there is a significant difference $(p=$ $0.042)$ in the concentration of $\mathrm{HbCO}$ at the $95 \%$ confidence level. However, the small number of cases $(n=9)$ where cardiac and femoral blood were both available and the proximity of the p-value to the significance threshold (0.05) should be kept in mind and temper the weight placed on these statistical conclusions. Further tests with larger sample sizes would be necessary to assess any significant difference between the two types of blood.

\section{4 | DISCUSSION}

\subsection{Quantification of $\mathrm{HbCO}$ in neonates}

Normal HbCO levels have been found to be below $1.5 \%$ for non-smokers and up to $15 \%$ for cigarette smokers ${ }^{16}$. The fact that the apparent $\mathrm{HbCO}$ in infants under 3 months of age went up to $25 \%$ in this study strongly suggests that the results were biased towards positive values due to the presence and interference of $\mathrm{HbF}$. This study focused on neonates under 4 months of age, 
when the fetal hemoglobin proportion is higher ${ }^{9}$. Only 4 samples of infants aged from 4 months to 1 year were analyzed, therefore there is no sufficient experimental evidence to draw definitive conclusions regarding the measurement of $\mathrm{HbCO}$ in that age range. However, after 4 months, there is a rapid transition from $\mathrm{HbF}$ to $\mathrm{HbA}$. In the results presented here, this transition translated into a rapid decrease of the apparent $\mathrm{HbCO}$ concentration as the age of the neonate increased. Therefore, $\mathrm{HbF}$ interference in $\mathrm{HbCO}$ measurements in infants of 4 months and older is unlikely. Prediction interval boundaries in Figure 2 showed the range of $\mathrm{HbCO}$ concentrations likely to be measured in neonate blood from 0 to 4 months. Measurement of additional samples would help refine these boundaries and help in the interpretation of $\mathrm{HbCO}$ measurements in neonate cases.

These results do not exclude other exogenous factors that could give rise to high levels of $\mathrm{HbCO}$. $\mathrm{HbF}$ has a greater affinity with $\mathrm{CO}$ than adult hemoglobin (2.5-3 times $)^{17}$. If the babies were exposed to a smoking environment prior to death or hospitalisation, it is likely that their $\mathrm{HbCO}$ level would be higher than normal. However, given that the half-life of carboxyhemoglobin is about 7 hours in fetal blood ${ }^{17,18}$, this should not be an issue for ante-mortem samples, since they came from children hospitalised in a nonsmoking area. Given that the post-mortem results are not significantly different from ante-mortem results, we infer that, in aggregate, the post-mortem cases did not present elevated $\mathrm{HbCO}$ levels due to environmental exposure.

\subsection{Impact of sodium dithionite}

Sodium dithionite is used to convert all forms of hemoglobin into reduced hemoglobin except for carboxyhemoglobin. Variend et al. ${ }^{14}$ reported that reduction of blood with sodium dithionite eliminates the interference of $\mathrm{HbF}$ and should eliminate the positive bias. However, our results showed that addition of sodium dithionite did not completely eliminate the interference from $\mathrm{HbF}$. In order to verify that this was not due to slow reaction kinetics, the quantity of dithionite was tripled (60 $\mathrm{mg}$ for $50 \mu \mathrm{L}$ of blood) and incubation time was increased up to 30 minutes. The results did not change after these modifications. No difference between Variend et al. protocol and the one used here was found to explain the discordant results. The one notable difference is the alternative wavelengths used by some authors (534 nm and $579 \mathrm{~nm}$ instead of $530 \mathrm{~nm}$ and $560 \mathrm{~nm}$ ). However, this is known to be a difference attributable to the absence of strong base $(1 \mathrm{~N} \mathrm{NaOH})$ in the preparation, which shifts the spectrum and thus the peaks of absorption ${ }^{15}$. The only conclusion is that sodium dithionite does not allow reduction of all fetal hemoglobin and proper elimination of its interference.

\subsection{Comparison of ante-mortem and post-mortem cases}

No significant difference between the measurements in ante-mortem and post-mortem cases was found. Therefore, future studies on the subject of $\mathrm{HbCO}$ in neonates could be conducted on ante-mortem blood, which is more easily available than post-mortem specimens. This would allow a larger sampling of the population and a more complete statistical analysis.

\subsection{Comparison of cardiac and femoral blood}

No strong conclusion can be given as to whether there is a significant difference between the measurements in cardiac and femoral blood in infants. Additional tests should be done on a larger sample size in order to indicate if pooled cardiac blood could confidently be used to quantify $\mathrm{HbCO}$ in whole blood. This piece of information would be particularly important in neonate cases, where the volume of available femoral blood is much reduced (average of $2 \mathrm{~mL}$ collected). Femoral blood could therefore be kept for quantification of analytes more subject to post-mortem redistribution phenomena.

\section{5 | CONCLUSION}

The false elevation of neonates' carboxyhemoglobin, as determined by spectrophotometric measurements, is an important piece of information for forensic toxicologists, coroners, pathologists and health professionals. It can help in the determination of the cause of death, or in the use of an adequate treatment for carbon monoxide poisoning. Because of false positives, HbCO results for newborns under 4 months of age must be interpreted with care. We showed that $\mathrm{HbCO}$ values of $14 \%$ to $34 \%$ are likely to be obtained at 2 weeks of age, whereas this interval goes down to $0 \%$ to $21 \%$ at 3 months. Confirmation by a second method (e.g. gas chromatography) is strongly recommended for more accurate measurements. Another option would be the use of a 
neonate specific calibration curve with the current spectrophotometric method. However, due to the rapid change in $\mathrm{HbF}$ levels in neonates, this is a difficult technique to set up. Ideally, the spectrophotometric method should be modified to be resistant to $\mathrm{HbF}$ interference.

\section{6 | ACKNOWLEDGEMENTS}

The authors wish to thank Jessica Aubé-Lapointe and Maxime Gosselin from the Laboratoire de sciences judiciaires et de médecine légale for their technical work and revision of the manuscript, and Dr. Cameron D. Skinner from Concordia University for revision of the paper.

\section{References}

1. Hall JE. Guyton and Hall Textbook of Medical Physiology. Philadelphia, United States: Elsevier. 12 ed. 2010.

2. Vallon JJ. Intoxication oxycarbonéech. 5: 127-145; Paris, France: Elsevier . 1998.

3. Baselt RC, Cravey RH. Disposition of Toxic Drugs \& Chemicals in Man. Foster City, United States: Biomedical Publications. 7 ed. 2004.

4. Katsumata Y, Aoki M, Sato K, Suzuki O, Oya M, Yada S. A simple spectrophotometry for determination of carboxyhemoglobin in blood. Journal of Forensic Science 1982; 27(4): 928-934. doi: 10.1520/JFS12212J

5. Feiner JR, Rollins MD, Sall J, Eilers H, Au P, Bickler PE. Accuracy of carboxyhemoglobin detection by pulse CO-oximetry during hypoxemia. Anesthesia and Analgesia 2013; 117(4): 847-858. doi: 10.1213/ANE.0b013e31828610a0

6. Boumba VA, Vougiouklakis T. Evaluation of the methods used for carboxyhemoglobin analysis in postmortem blood. International Journal of Toxicology 2005; 24(4): 275-281. doi: 10.1080/10915810591007256

7. Vreman H, Ronquillo R, Ariagno R, Schwartz H, Stevenson D. Interference of fetal hemoglobin with the spectrophotometric measurement of carboxyhemoglobin. Clinical Chemistry 1988; 34(4): 975-977. doi: 10.1093/clinchem/34.5.975

8. Mehrotra S, Edmonds M, Lim RK. False elevation of carboxyhemoglobin: case report. Pediatric Emergency Care 2011; 27(2): 138-140. doi: 10.1097/PEC.0b013e318209f076

9. Fraser I, Raper A. Observations on the change from foetal to adult erythropoiesis. Archives of Disease in Childhood 1962; 37(193): 289-296-. doi: 10.1136/adc.37.193.289

10. Fogh-Andersen N, Siggaard-Andersen O, Lundsgaard FC, Wimberley PD. Spectrophotometric determination of hemoglobin pigments in neonatal blood. Clinica Chimica Acta 1987; 166(2-3): 291-296. doi: 10.1016/00098981(87)90432-3

11. Venning H, Roberton D, Milner A. Carbon monoxide poisoning in an infant. British Medical Journal (Clinical Research Ed.) 1982; 284(6316): 651. doi: 10.1136/bmj.284.6316.651

12. Zijlstra W, Buursma A, Roest M.-V. dW. Absorption spectra of human fetal and adult oxyhemoglobin, de-oxyhemoglobin, carboxyhemoglobin, and methemoglobin. Clinical Chemistry 1991; 37(9): 1633-1638. doi: 10.1093/clinchem/37.9.1633

13. Zwart A, Siepel H, Heerspink W. A new method for the determination of carboxyhemoglobinin blood of newborns. Possible clinical implications of elevated levels. Scandinavian Journal of Clinical and Laboratory Investigation 1990; 50(Sup203): 253-259. doi: 10.3109/00365519009087519

14. Variend S, Forrest A. Carbon monoxide concentrations in infant deaths. Archives of Disease in Childhood 1987; 62(4): 417-418. doi: 10.1136/adc.62.4.417

15. Katsumata Y, Aoki M, Sato K, Oya M, Yada S, Suzuki O. A simple spectrophotometric method for the determination of carboxyhemoglobin in blood. Forensic Science International 1981; 18(2): 175-179. doi: 10.1016/0379-0738(81)90157-2 
16. Light A, Grass C, Pursley D, Krause J. Carboxyhemoglobin levels in smokers vs. non-smokers in a smoking environment. Respiratory Care 2007; 52(11): 1576.

17. Hill E, Hill J, Power G, Longo L. Carbon monoxide exchanges between the human fetus and mother: a mathematical model. American Journal of Physiology - Heart and Circulatory Physiology 1977; 232(3): H311-H323. doi: 10.1152/ajpheart.1977.232.3.H311

18. Weaver LK. Carbon Monoxide Poisoning. New England Journal of Medicine 2009; 360(12): 1217-1225. doi: 10.1056/NEJMcp0808891

How to cite this article: Lucie Vaillancourt, Brigitte Desharnais, Nathalie Goudreau, and Pascal Mireault (2016), Interference of fetal hemoglobin in the determination of carboxyhemoglobin by spectrophotometry, Canadian Society of Forensic Science Journal, 49:2, 69-77, DOI: 10.1080/00085030.2015.1115692 